\title{
Sunitinib added to FOLFIRI versus FOLFIRI in patients with chemorefractory advanced adenocarcinoma of the stomach or lower esophagus: a randomized, placebo-controlled phase II AIO trial with serum biomarker program
}

Markus Moehler ${ }^{1 *+}$, Irina Gepfner-Tuma ${ }^{1 \dagger}$, Annett Maderer ${ }^{1}$, Peter C. Thuss-Patience ${ }^{2}$, Joern Ruessel ${ }^{3}$, Susanna Hegewisch-Becker ${ }^{4}$, Hansjochen Wilke ${ }^{5}$, Salah-Eddin Al-Batran ${ }^{6}$, Mohammad-Reza Rafiyan ${ }^{6}$, Florian Weißinger ${ }^{7}$, Hans-Joachim Schmoll ${ }^{3}$, Frank Kullmann ${ }^{8}$, Ludwig Fischer von Weikersthal ${ }^{9}$, Jens T. Siveke ${ }^{10}$, Jens Weusmann", Stephan Kanzler ${ }^{11}$, Carl Christoph Schimanski ${ }^{12}$, Melanie Otte ${ }^{13}$, Lukas Schollenberger ${ }^{14}$, Jochem Koenig ${ }^{15}$ and Peter R. Galle

\footnotetext{
Abstract

Background: As a multi-targeted anti-angiogenic receptor tyrosine kinase (RTK) inhibitor sunitinib (SUN) has been established for renal cancer and gastrointestinal stromal tumors. In advanced refractory esophagogastric cancer patients, monotherapy with SUN was associated with good tolerability but limited tumor response.

Methods: This double-blind, placebo-controlled, multicenter, phase II clinical trial was conducted to evaluate the efficacy, safety and tolerability of SUN as an adjunct to second and third-line FOLFIRI (NCT01020630). Patients were randomized to receive 6-week cycles including FOLFIRI plus sodium folinate (Na-FOLFIRI) once every two weeks and SUN or placebo (PL) continuously for four weeks followed by a 2-week rest period. The primary study endpoint was progression-free survival (PFS). Preplanned serum analyses of VEGF-A, VEGF-D, VEGFR2 and SDF-1a were performed retrospectively.

Results: Overall, 91 patients were randomized, 45 in each group (one patient withdrew). The main grade $\geq 3$ AEs were neutropenia and leucopenia, observed in $56 \% / 20 \%$ and $27 \% / 16 \%$ for FOLFIRI + SUN/FOLFIRI + PL, respectively. Median PFS was similar, 3.5 vs. 3.3 months (hazard ratio (HR) 1.11, $95 \% \mathrm{Cl} 0.70-1.74, P=0.66$ ) for FOLFIRI + SUN vs. FOLFIRI + PL, respectively. For FOLFIRI + SUN, a trend towards longer median overall survival (OS) compared with placebo was observed (10.4 vs. 8.9 months, HR $0.82,95 \% \mathrm{Cl} 0.50-1.34$, one-sided $P=0.21$ ). In subgroup serum analyses, significant changes in VEGF-A $(P=0.017)$, VEGFR2 $(P=0.012)$ and VEGF-D $(P<0.001)$ serum levels were observed.

(Continued on next page)
}

\footnotetext{
* Correspondence: markus.moehler@unimedizin-mainz.de

${ }^{\dagger}$ Equal contributors

${ }^{1}$ University Medical Center, Johannes Gutenberg-University Mainz, I.

Medizinische Klinik und Poliklinik, Langenbeckstraße 1, 55131 Mainz,

Germany

Full list of author information is available at the end of the article
} 
(Continued from previous page)

Conclusions: Although sunitinib combined with FOLFIRI did not improve PFS and response in chemotherapyresistant gastric cancer, a trend towards better OS was observed. Further biomarker-driven studies with other anti-angiogenic RTK inhibitors are warranted.

Trial registration: This study was registered prospectively in the NCT Clinical Trials Registry (ClinicalTrials.gov) under NCT01020630 on November 23, 2009 after approval by the leading ethics committee of the Medical Association of Rhineland-Palatinate, Mainz, in coordination with the participating ethics committees (see Additional file 2) on September 16, 2009.

Keywords: Chemorefractory advanced gastric cancer, Tyrosine kinase inhibitor, Sunitinib, FOLFIRI, VEGF

Abbreviations: AIO, Arbeitsgemeinschaft Internistische Onkologie

\section{Background}

Overall survival (OS) for patients with locally advanced and metastatic gastric cancer (AGC) remains poor with a median OS of 8-11 months [1-3]. Many clinical trials have investigated novel first-line chemotherapeutic combinations without demonstrating a clear survival benefit compared with standard regimens $[1,4,5]$. Several prospective randomized trials indicate a significant increase in OS for second-line chemotherapy compared with best supportive care (BSC) [6,7]. Although none of the investigated combination regimens demonstrated significant advantages over the others, the combination of irinotecan, 5-fluorouracil (5-FU) and folinic acid (FOLFIRI) is accepted as a safe and efficient chemotherapeutic treatment for patients with refractory AGC [2].

Tumor angiogenesis, growth and metastasis can be inhibited by blocking receptor tyrosine kinases (RTKs) which are known to be overexpressed in human gastric cancer (GC), including vascular endothelial growth factor receptors (VEGFRs) or platelet-derived growth factor receptors (PDGFRs) [3, 8]. Furthermore, disease progression or poor survival is associated with VEGF-A, epithelial growth factor receptor (EGFR) and PDGF-A expression in the tumor $[9,10]$. Serum VEGF levels are significantly higher in GC patients with remaining tumor and decrease with radical resection. High preoperative serum VEGF-A correlate with poor survival, tumor invasion and distant metastases [11]. In contrast, in GC patients treated with the VEGF-A antibody bevacizumab high plasma VEGF-A predicted improved OS $[12,13]$. Interestingly, the prognostic significance of VEGF-A concentrations could be demonstrated for non-Asian population only [12, 14]. Additionally, a correlation of VEGF expression in GC tumor tissue with histopathological response was shown $[11,13,15,16]$.

Agents such as gefitinib, erlotinib and cetuximab specifically target RTKs through a dominant receptor pathway and have been investigated in phase II-III studies in patients with AGC [17]. However, in many tumors, several RTKs are co-expressed [8]. In addition, the initiation of alternative angiogenesis signaling pathways under therapy with anti-angiogenic agents represents a potential cause for therapy resistance of tumor cells [18-20]. Stromal cell-derived factor-1 (SDF-1 $\alpha$ ), also known as CXCL12, may induce proliferation, dissemination and immune evasion of several tumor tissues with several existing variants $[18,19,21-23]$. However, studies investigating its expression in GC specimens have revealed inconsistencies regarding its occurrence in cancer tissue and its correlation with clinical characteristics [24, 25].

Sunitinib malate (SUN) is an oral, multi-targeted RTK inhibitor of VEGFR-1, -2 and -3 , PDGFR- $\alpha$ and $-\beta$ and several other RTKs [26, 27] and may have additional benefits compared to single receptor targeted inhibition. In two recent phase II studies in patients with chemorefractory AGC, SUN showed promising activity and manageable toxicity $[28,29]$. Therefore, this phase II clinical trial was conducted to evaluate the efficacy, safety and tolerability of SUN versus placebo (PL) as add-on therapy to the second-line FOLFIRI treatment regimen.

\section{Methods}

\section{Study design and treatment}

This randomized, double-blind, placebo-controlled, multicenter, phase II study was conducted at 15 sites in Germany after approval of the leading and the local ethics committees. It was performed according to the International Conference on Harmonisation - Good Clinical Practice and the Declaration of Helsinki and was registered in the public NCT Clinical Trials Registry (ClinicalTrials. gov) under NCT01020630.

After signing informed consent, patients (SUN-CASE inclusion/exclusion criteria: Additional file 1: Table S1) were randomized to receive either $\mathrm{SUN}$ or $\mathrm{PL}$ in addition to the two-weekly FOLFIRI plus sodium folinate (Na-FOLFIRI) chemotherapy backbone. Patients were treated until occurrence of any of the following: progressive disease, intolerable adverse events (AEs), any AE that resulted in treatment interruption of $>14$ days within the active treatment cycle or $>4$ weeks between consecutive active treatment cycles, or withdrawal of consent. 
SUN (starting dose: $25 \mathrm{mg}$ ) or PL was administered orally once daily for four consecutive weeks followed by a 2-week rest period. The dose of SUN could be increased to $37.5 \mathrm{mg}$ at the discretion of the treating physician and upon approval by the Data and Safety Monitoring Board (DSMB) in patients tolerating $25 \mathrm{mg}$ in the first cycle without dose-limiting toxicities. The dose could be reduced to $12.5 \mathrm{mg}$ in patients experiencing SUN-related toxicity.

FOLFIRI was administered as the following regimen: Irinotecan $\left(180 \mathrm{mg} / \mathrm{m}^{2}\right)$ was given intravenously on day 1 , immediately followed by 5 -FU bolus $\left(400 \mathrm{mg} / \mathrm{m}^{2}\right)$ and $46-\mathrm{h}$ infusion of sodium folinate $\left(400 \mathrm{mg} / \mathrm{m}^{2}\right)$ and 5 -FU $\left(2000 \mathrm{mg} / \mathrm{m}^{2}\right)$ every two weeks, i.e. three courses of FOLFIRI in every 6-week SUN/PL cycle [30]. Treatment continued until disease progression or occurrence of unacceptable toxicity/AEs.

\section{Biomarker analysis}

An important inclusion criterion was the existance of at least one blood sample before first medication intake (baseline) and a further available sample during the study. The peripheral blood samples were collected at all 15 participating study centers. After collection, specimens were centrifuged to separate the serum which was stored at $-80{ }^{\circ} \mathrm{C}$. Serum samples were tested in duplicate for concentrations of VEGF-A, VEGF-D, soluble VEGFR2 and SDF- $1 \alpha$ on days $1+14$ of the first cycle. Furthermore, premedication serum samples from day 1 of cycle 2 and cycle 3 were evaluated. The following enzyme-linked immunosorbent assays (Duo-ELISA - R\&D, Minneapolis) were performed for quantification of serum levels using standard curves for concentration calculation: Duoset ${ }^{\circ}$ ELISA Human VEGF (DY293B), Duoset ${ }^{\oplus}$ ELISA Human VEGFD/FIGF (DY622), Duoset ${ }^{\oplus}$ ELISA Human VEGFR2/KDR (DY357) and Duoset ${ }^{\oplus}$ ELISA Human CXCL12/SDF1 (DY350) according to manufacturer's protocols.

\section{Safety and efficacy assessment}

AEs were graded according to the National Cancer Institute (NCI) Common Terminology Criteria for AEs (CTCAE), version 4.0.

Tumor response was measured by computed tomography scan after cycle 1 and 2, then after every 2 cycles, assessed and graded by RECIST 1.1. Screening assessments were carried out within 28 days prior to the start of treatment. After the end of treatment (EOT), an EOT visit was performed within 30 days. Patients were followed-up every 3 months for 1 year thereafter.

\section{Trial objectives and statistical analysis}

The primary endpoint was progression-free survival (PFS) according to RECIST 1.1. Secondary endpoints were objective response rate, tumor control rate (complete response $[\mathrm{CR}]+$ partial response $[\mathrm{PR}]+$ stable disease [SD]), duration of disease stabilization, 1-year OS, and the safety and tolerability of the placebocontrolled combination therapy compared to the standard second-line therapy.

In total, 90 patients were to be enrolled to assign 43 patients to each treatment arm, taking into account a drop-out rate of $5 \%$. A median PFS of 3 months was assumed for the control group. A total of 86 events had to be observed to show a $50 \%$ improvement (4.5 months median PFS) under SUN versus PL to ensure a power of $80 \%$, at a one sided significance level $\alpha$ of $15 \%$.

All statistical analyses were performed using SPSS $^{\circ}$ Statistics. Measured biomarker values were partially logtransformed for statistical purposes. Kaplan-Meier analysis with log-rank test was performed to estimate PFS and OS. Cox proportional hazards model was used for survival and covariates analyses. Proportions of adverse events were compared by chi-square test or Fisher's exact test if the event occurred in less than 10 patients. Non-parametric Wilcoxon-tests were used to compare serum levels between different samples. To assess correlations between serum levels and clinical parameters, Spearman coefficients, non-parametric Mann-Whitney and Jonckheere-Terpstra tests were performed. Tests with $P<0.05$ were considered statistically significant.

The primary analysis population was the intention-totreat (ITT) set comprising all patients with at least one available post-baseline assessment of the primary analysis variable. The safety analysis included all patients who had received at least one dose of trial medication. The analysis of secondary endpoints and all further data were interpreted descriptively.

\section{Results}

\section{Patient characteristics}

Overall, 91 patients were enrolled (Fig. 1). One patient withdrew consent immediately after randomization and was not included in the ITT analysis (SUN/PL 45/45).

Demographic and baseline characteristics for the ITT patient population compared with the evaluable population for serum analysis are provided in Table 1.

Follow-up for progressive disease (PD) was carried out at $3,6,9$ and 12 months ( \pm 2 weeks) after the EOT visit until progression. Progression was observed in 32 and 31 patients of the SUN and PL groups, respectively. In $6 / 9$ of SUN/PL patients, respectively, progression was observed $>12$ months after the EOT visit. At the end of the study, 7/5 of SUN/PL patients were reported to have no signs of PD.

\section{Treatment}

Patients in both groups started 2.7 cycles of treatment. In total, 29 and 24 patients from the SUN and PL groups 


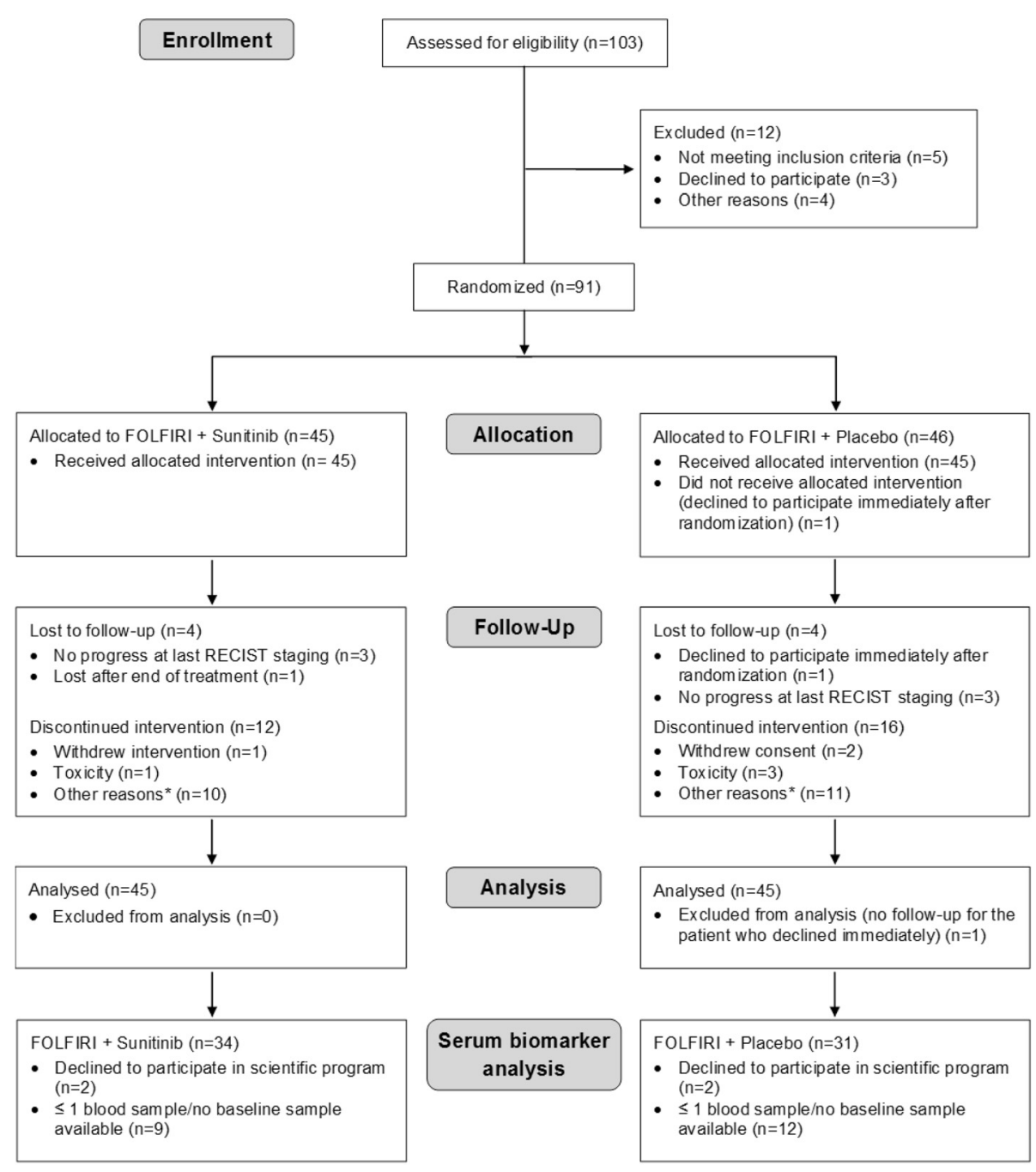

* Patients wish (SUN/PL 2/4), palliative radiation (0/1), gastrectomy (0/1), late discontinuation, without signs of progression after more than 150 days of treatment (2/2), worsening of general health condition $(2 / 0)$ or without a specified reason given (4/3)

Fig. 1 Consort flow diagram

respectively, terminated treatment due to disease progression. Further reasons for ending treatment (SUN/ PL) were treatment interruption ( $3 / 2$ patients), toxicity (1/3 patients) and withdrawal of informed consent (1/2 patients).

\section{Efficacy}

Efficacy analysis was carried out on the ITT population. Figure 2 illustrates the survival distribution per treatment group for PFS and OS by Kaplan-Meier curves. The median PFS was similar in both groups, 107 and 99 days (3.5 vs. 3.3 months) for SUN and PL patients, respectively (HR 1.11, $95 \% \mathrm{CI} 0.70-1.74, P=0.66$ ). The OS showed a trend in favor of SUN compared with PL,
315 vs. 270 days (10.4 vs. 8.9 months). However, the difference was not statistically significant (HR 0.82, $95 \%$ CI $0.50-1.34, P=0.42$ ). The probability of 1 -year survival was $34 \%$ and $36 \%$, and the probability of living 180 days was 0.65 and 0.57 for the SUN and PL groups, respectively.

Evaluation of response and tumor control was performed in the ITT population (Table 1). Best responses according to RECIST 1.1 were defined in 79 patients (Table 1). Objective response and tumor control were achieved in $20 \% / 29 \%$ and $58 \% / 56 \%$ for FOLFIRI + SUN/FOLFIRI + PL, respectively. Disease progression was the cause of death in $32 \%$ of patients treated with SUN and in $31 \%$ of PL patients. 
Table 1 Demographic, baseline and response characteristics in the ITT population and serum analysis subpopulation

\begin{tabular}{|c|c|c|c|c|c|c|c|c|}
\hline \multirow[t]{3}{*}{ Characteristic } & \multicolumn{4}{|c|}{ ITT population } & \multicolumn{4}{|c|}{ Serum analysis population } \\
\hline & \multicolumn{2}{|c|}{ Sunitinib } & \multicolumn{2}{|c|}{ Placebo } & \multicolumn{2}{|c|}{ Sunitinib } & \multicolumn{2}{|c|}{ Placebo } \\
\hline & $N$ & $n(\%)$ & N & $n(\%)$ & $N$ & $n(\%)$ & $N$ & $n(\%)$ \\
\hline Number of patients & 45 & 100 & 45 & 100 & 34 & 100 & 31 & 100 \\
\hline \multicolumn{9}{|l|}{ Age (years) } \\
\hline Mean (SD) & \multicolumn{2}{|c|}{$59(11)$} & \multicolumn{2}{|c|}{$57(11)$} & \multicolumn{2}{|c|}{$57(12)$} & \multicolumn{2}{|c|}{$58(12)$} \\
\hline \multirow[t]{2}{*}{ Median (Range) } & \multicolumn{2}{|l|}{62} & \multicolumn{2}{|l|}{57} & \multicolumn{2}{|l|}{60} & \multicolumn{2}{|c|}{60} \\
\hline & \multicolumn{2}{|c|}{$(37-76)$} & \multicolumn{2}{|c|}{$(28-84)$} & \multicolumn{2}{|c|}{$(37-76)$} & \multicolumn{2}{|c|}{$(28-84)$} \\
\hline
\end{tabular}

Gender

Male

Female

$\begin{array}{lll}33 & 30 & 67\end{array}$

67

$12 \quad 27$

15

33

25

74

58

Karnofsky performance status

90-100\%

$27 \quad 60$

$70-80 \%$

$16 \quad 36$

26

58

9

26

42

Not known

2

Histology: Adenocarcinoma of

Stomach

Cardia

Not known

Treatment lines before study entry

1
2
3

Not known

Screening pT-stadium

$$
\begin{aligned}
& 0 \\
& 1 \\
& 2 \\
& 3 \\
& 4 \\
& x
\end{aligned}
$$

$\begin{array}{ll}22 & 49 \\ 23 & 51 \\ 0 & 0\end{array}$

18

$$
40
$$

65
29
6

18
13

58

$\begin{array}{lll}0 & 2 & 4\end{array}$

\section{1}

44

4

2

6

$\begin{array}{ll}19 & 61 \\ 11 & 25 \\ 1 & 3\end{array}$

\section{1}

17

50
50
0

$\begin{array}{ll}17 & 55 \\ 14 & 45 \\ 0 & 0\end{array}$

0

0

0

Screening pN-stadium

0
1
+
2
3
$x$

$\begin{array}{ll}2 & 4 \\ 16 & 36 \\ - & - \\ 9 & 20 \\ 8 & 18 \\ 10 & 22\end{array}$

Screening pM-stadium

0
1

$\begin{array}{ll}9 & 20 \\ 36 & 80\end{array}$

$\begin{array}{ll}34 & 76 \\ 11 & 24 \\ - & - \\ 0 & 0\end{array}$

26
6
2
0

$\begin{array}{lll}76 & 24 & 77 \\ 18 & 7 & 23 \\ 6 & - & - \\ 0 & 0 & 0\end{array}$

$\begin{array}{llll}- & - & 1 & 2 \\ 1 & 2 & 1 & 2 \\ 5 & 11 & 7 & 16 \\ 21 & 47 & 18 & 40 \\ 7 & 16 & 9 & 20 \\ 11 & 24 & 9 & 20\end{array}$

-
1
4
17
6
6

$\begin{array}{lll}- & 1 & 3 \\ 3 & 1 & 3 \\ 12 & 6 & 19 \\ 50 & 9 & 29 \\ 18 & 7 & 23 \\ 18 & 7 & 23\end{array}$

Best response

Complete response (CR)

Partial response (PR)

$\begin{array}{ll}- & - \\ 9 & 20\end{array}$

$\begin{array}{ll}7 & 16 \\ 11 & 24 \\ 1 & 2 \\ 8 & 18 \\ 6 & 13 \\ 12 & 27\end{array}$

16
24
2
18
13
27

1
16
-
7
7
3

$\begin{array}{lll}3 & 6 & 19 \\ 47 & 7 & 23 \\ - & - & - \\ 21 & 7 & 23 \\ 21 & 5 & 16 \\ 9 & 6 & 19\end{array}$

$\begin{array}{llllll}4 & 9 & 8 & 24 & 3 & 10 \\ 41 & 91 & 26 & 77 & 28 & 90\end{array}$


Table 1 Demographic, baseline and response characteristics in the ITT population and serum analysis subpopulation (Continued)

\begin{tabular}{lllllllll}
\hline Stable disease (SD) & 18 & 40 & 12 & 27 & 17 & 50 & 9 & 29 \\
Progressive disease (PD) & 14 & 31 & 16 & 36 & 8 & 24 & 12 & 39 \\
$\quad$ Not evaluable & 4 & 9 & 4 & 9 & 1 & 3 & - & - \\
Objective response (CR + PR) & 9 & 20 & 13 & 29 & 8 & 24 & 10 \\
Tumor control rate (CR + PR + SD) & 27 & 60 & 25 & 56 & 25 & 74 & 19 \\
\hline
\end{tabular}

$S D$ standard deviation
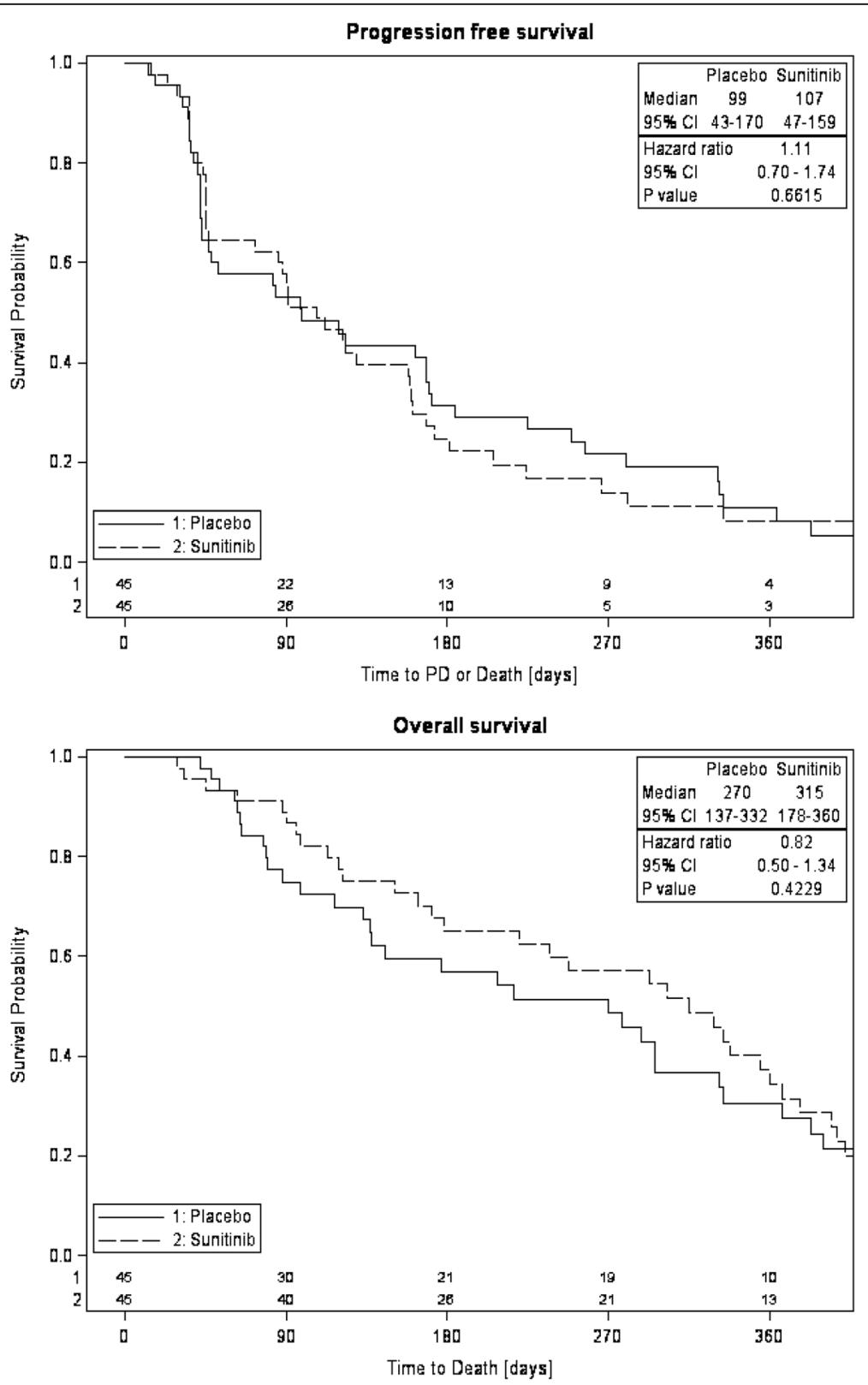

Fig. 2 Kaplan-Meier curves for progression-free survival and overall survival in the primary analysis population (ITT). Hazard ratios estimated by Cox proportional hazards model. PFS, progression-free survival; HR, hazard ratio; ITT, intention-to-treat 


\section{Safety and tolerability}

Overall, 43 SUN and 42 PL patients experienced at least one AE. In total, $33 \mathrm{SUN}$ and $31 \mathrm{PL}$ patients had at least one AE CTC-Grade $>3$. CTC-Grade 4 and Grade 5 AEs were reported in $15 / 7$ and $3 / 5$ of SUN/PL patients, respectively. The frequencies of grade $\geq 3$ AEs are shown in Table 2.

AEs of Grade $\geq 3$ at least possibly related to study medication comprised neutropenia (24/8), leucopenia $(11 / 5)$, diarrhea $(0 / 4)$, mucosal inflammation $(2 / 2)$, fatigue $(0 / 3)$, pulmonary embolism $(2 / 1)$, nausea $(1 / 2)$, and vomiting $(2 / 1)$ for SUN/PL patients, respectively. With the notable exception of neutropenia $(P<0.001)$, all proportions of patients exhibiting an $\mathrm{AE}$ were statistically not significant. No unexpected toxicities/AEs occurred with SUN.

\section{Biomarker analysis}

No significant correlations of any biomarker levels to age, gender, lymph node or distant metastases were found. Similar PFS and OS results in the observed subgroup and the ITT population, suggest an absence of bias. Tables 3 and 4 summarize the main findings.

Table 2 Frequency of adverse events grade $\geq 3$, reported in $\geq 2$ (4\%) of patients of either group regardless of causality

\begin{tabular}{|c|c|c|c|c|}
\hline \multirow[t]{2}{*}{ Adverse events } & \multicolumn{2}{|c|}{ Sunitinib plus FOLFIRI ${ }^{a}$} & \multicolumn{2}{|c|}{ Placebo plus FOLFIRI $^{\mathrm{a}}$} \\
\hline & $N=45$ & $100 \%$ & $N=45$ & $100 \%$ \\
\hline Neutropenia & 25 & 56 & 9 & 20 \\
\hline Leucopenia & 12 & 27 & 7 & 16 \\
\hline Diarrhea & 1 & 2 & 6 & 13 \\
\hline Nausea & 3 & 7 & 3 & 7 \\
\hline Vomiting & 3 & 7 & 3 & 7 \\
\hline Fatigue & - & - & 4 & 9 \\
\hline Pain & - & - & 4 & 9 \\
\hline Pulmonary embolism & 2 & 4 & 2 & 4 \\
\hline $\begin{array}{l}\text { General physical health } \\
\text { deterioration }\end{array}$ & 2 & 4 & 2 & 4 \\
\hline Mucosal inflammation & 2 & 4 & 2 & 4 \\
\hline $\begin{array}{l}\text { Gamma-glutamyltransferase } \\
\text { increased }\end{array}$ & 3 & 7 & 1 & 2 \\
\hline Pneumonia & - & - & 3 & 7 \\
\hline Subileus & - & - & 3 & 7 \\
\hline $\begin{array}{l}\text { Blood acid phosphatase } \\
\text { increased }\end{array}$ & 2 & 4 & - & - \\
\hline Blood bilirubin increased & 2 & 4 & - & - \\
\hline
\end{tabular}

FOLFIRI 5-fluorouracil, leucovorin and irinotecan

aSchedule: 4/2, 4 weeks on treatment, followed by 2 weeks off; dosage: starting dose $25 \mathrm{mg} /$ day

Neutropenia: $p<0.001$, leucopenia $p=0.20$, all other items statistically not significant (Fisher's exact test)

\section{SDF-1a/CXCL12}

Blood samples of 50 patients were available for biomarker analysis of SDF-1 $\alpha$. A significant increase of SDF-1 $\alpha$ from median baseline levels of $143 \mathrm{pg} / \mathrm{ml}$ to $337 \mathrm{pg} / \mathrm{ml}$ at day 1 of cycle 2 was detected for PL only (Wilcoxon matched-pairs test $P=0.041$ ). No significant benefit for PFS or OS could be shown in the small subgroup of this biomarker analysis. A trend for longer PFS in both treatment arms with an increase in SDF-1 $\alpha$ from baseline to cycle 2 was shown (Wilcoxon matched-pairs test $P=0.058)$.

\section{VEGF-A}

The median baseline serum level of VEGF-A was $58.7 \mathrm{pg} / \mathrm{ml}$ for 65 evaluable patients. There was a significant reduction in VEGF-A levels from baseline to day 14 of the first cycle in the SUN group (Wilcoxon matchedpairs test $P=0.017)$. Interestingly, we detected a significant decrease of VEGF-A levels from baseline to day 1 of cycle 2 for the PL group only $(P=0.033)$. For the PL group, a similar trend towards reduction of VEGF-A levels from baseline to day 1 of cycle 3 could be shown $(P=0.062)$. In contrast, no change between baseline and day 1 of cycle 2 could be shown for patients receiving SUN. Moreover, this result was supported by a trend to an increase in VEGF-A concentration from day 14 of cycle 1 to predose measurement on day 1 of cycle 2 for the SUN group only $(P=0.10)$. A VEGF-A reduction from baseline to day 14 of cycle 1 correlated positively with longer OS in the PL group only (HR 0.286, $95 \% \mathrm{CI}$ 0.101-0.814, $P=0.019$ ).

Independent of treatment, low VEGF-A baseline values were significantly associated with longer PFS (Fig. 3). Additionally, a strong trend to a longer OS of 11.07 months \pm 63 days for the group with low VEGF-A baseline levels versus 7.56 months \pm 73 days (HR 0.602, $95 \%$ CI $0.356-1.018, P=0.058)$ was detected.

\section{sVEGFR2}

The median concentration of sVEGFR2 prior to the start of study treatment was $4688 \mathrm{pg} / \mathrm{ml}$ for 65 evaluable patients. Analysis of serum values showed significantly decreased sVEGFR2 after 14 days drug intake during cycle 1 in the SUN group (Wilcoxon matched-pairs test $P=$ 0.012). A change from a median level of $4613 \mathrm{pg} / \mathrm{ml}$ to $4197 \mathrm{pg} / \mathrm{ml}$ after 14 days was observed. Furthermore, concentrations on day 1 of cycle 2 were significantly lower than baseline in the SUN group $(4238 \mathrm{pg} / \mathrm{ml}$, Wilcoxon matched-pairs test $P=0.006)$. Between baseline and day 1 of cycle 3 a similar trend for a total of 18 available patient samples with a median concentration of $4312 \mathrm{pg} / \mathrm{ml}$ could be shown $(P=0.078)$. In contrast no significant level changes could be determined for patients in the PL group. High sVEGFR2 baseline levels 
Table 3 Effects of study medication on biomarker serum levels

\begin{tabular}{|c|c|c|c|c|c|c|c|}
\hline \multirow{2}{*}{\multicolumn{2}{|c|}{$\begin{array}{l}\text { Serum biomarker } \\
\text { and study group }\end{array}$}} & \multicolumn{6}{|l|}{ Level changes $^{a}$} \\
\hline & & \multirow{2}{*}{$\begin{array}{l}\Delta \delta \text { day } 14 \text { of cycle } 1 \text { - baseline } \\
-0.6816(1.43)\end{array}$} & \multirow{2}{*}{$\begin{array}{l}P \text { value } \\
\mathbf{0 . 0 1 7}\end{array}$} & \multirow{2}{*}{$\begin{array}{l}\Delta \delta \text { day } 1 \text { of cycle } 2 \text { - baseline } \\
-0.1393(1.83)\end{array}$} & \multirow{2}{*}{$\begin{array}{l}P \text { value } \\
0.831\end{array}$} & \multirow{2}{*}{$\begin{array}{l}\Delta \delta \text { day } 1 \text { of cycle } 3 \text { - baseline } \\
0.1111(1.26)\end{array}$} & \multirow{2}{*}{$\frac{P \text { value }}{0.975}$} \\
\hline VEGF-A & Sunitinib & & & & & & \\
\hline & Placebo & $-0.3134(1.24)$ & 0.472 & $-0.7184(1.32)$ & 0.033 & $-1.1177(1.92)$ & 0.062 \\
\hline \multirow[t]{2}{*}{ sVEGFR2 } & Sunitinib & $-0.0648(0.17)$ & 0.012 & $-0.0854(0.12)$ & 0.006 & $-0.0727(0.14)$ & 0.078 \\
\hline & Placebo & $-0.0086(0.12)$ & 0.222 & $-0.0216(0.10)$ & 0.472 & $0.0306(0.20)$ & 0.910 \\
\hline \multirow[t]{2}{*}{ VEGF-D } & Sunitinib & $0.2476(0.26)$ & $<0.001$ & $0.1038(0.27)$ & 0.131 & $0.0914(0.20)$ & 0.133 \\
\hline & Placebo & $-0.1093(0.66)$ & 0.616 & $-0.0094(0.19)$ & 0.811 & $-0.1061(0.25)$ & 0.281 \\
\hline \multirow[t]{2}{*}{ SDF-1a } & Sunitinib & $0.0914(0.47)$ & 0.756 & $0.2912(0.92)$ & 0.730 & - & - \\
\hline & Placebo & $-0.0827(0.93)$ & 0.820 & $0.3572(0.85)$ & 0.041 & - & - \\
\hline
\end{tabular}

${ }^{a}$ Data are presented as mean (SD). $P<0.05$ marked in boldface and considered significant using paired Wilcoxon test

significantly correlated with a longer PFS (HR 1.682, $95 \%$ CI 1.014-2.789, $P=0.044$ ). Additionally, we found a relationship between high sVEGFR2 levels on day 1 of cycle 2 and longer PFS independent of treatment (HR 2.557, 95 \% CI 1.248-5.237, $P=0.010$ ) as shown in Fig. 4. However for OS, no association of sVEGFR2 was found in the analyses.

\section{VEGF-D}

Serum samples from 64 patients with a median baseline concentration of $712.4 \mathrm{pg} / \mathrm{ml}$ were available for analysis of VEGF-D. The comparison of VEGF-D levels between baseline and day 14 of cycle 1 showed a significant increase in the SUN group (Wilcoxon matched-pairs test with median values of $681 \mathrm{pg} / \mathrm{ml}$ to $913 \mathrm{pg} / \mathrm{ml}, P<$ 0.001 ), but no change in the PL group. Furthermore, a similar trend to higher VEGF-D levels on day 1 of cycle 2 was shown for patients receiving SUN $(681 \mathrm{pg} / \mathrm{ml}$ to $807 \mathrm{pg} / \mathrm{ml}, P=0.19$ ).
The population was then stratified into two groups depending on best response: 46 patients without objective response (stable disease or progression) and $18 \mathrm{pa}$ tients with a proven objective response (complete or partial response). For patients with an objective response, high VEGF-D baseline concentrations were associated with a longer PFS independent of treatment (11.1 vs. 4.1 months, HR $0.189,95 \%$ CI $0.056-0.637, P$ $=0.007$; Fig. 5). An analysis following patient separation into quartile groups according to their VEGF-D baseline concentration confirmed that the longest median PFS for patients were associated with the highest baseline values above the 75 percentile (HR 1.801, $95 \% \mathrm{CI}$ 1.033-3.141, $P=0.038)$. Moreover, high VEGF-D levels on day 1 of cycle 2 also correlated with significantly longer PFS in the group with objective response (HR 4.236, $95 \%$ CI $1.226-14.638, P=0.023$ ). Similar to sVEGFR2 however, no association of VEGF-D with OS was found, in the analyses.

Table 4 Association between biomarker serum levels and outcome

\begin{tabular}{|c|c|c|c|c|c|}
\hline \multicolumn{2}{|c|}{ Serum biomarker } & \multicolumn{2}{|l|}{ PFS } & \multicolumn{2}{|l|}{ OS } \\
\hline & & $\begin{array}{l}\text { Median } \\
\text { (days) }\end{array}$ & $\begin{array}{l}\mathrm{HR}(95 \% \mathrm{Cl}) \\
P \text { value }\end{array}$ & $\begin{array}{l}\text { Median } \\
\text { (days) }\end{array}$ & $\begin{array}{l}\mathrm{HR}(95 \% \mathrm{Cl}) \\
P \text { value }\end{array}$ \\
\hline \multirow{4}{*}{ VEGF-A } & & & & & \\
\hline & low-level baseline & 166 & 0.533 & 329 & 0.602 \\
\hline & high-level baseline & 91 & $(0.318-0.895)$ & 270 & $(0.356-1.018)$ \\
\hline & & & $P=0.017$ & & $P=0.058$ \\
\hline \multirow[t]{3}{*}{ sVEGFR2 } & low-level baseline & 107 & 1.682 & 293 & 1.148 \\
\hline & high-level baseline & 167 & $(1.014-2.789)$ & 330 & $(0.648-1.927)$ \\
\hline & & & $P=0.044$ & & $P=0.601$ \\
\hline \multirow[t]{3}{*}{ VEGF-D } & low-level baseline & 123 & 1.670 & 310 & 0.888 \\
\hline & high-level baseline & 159 & $(0.760-3.673)$ & 300 & $(0.527-1.496)$ \\
\hline & & & $P=0.200$ & & $P=0.654$ \\
\hline \multirow[t]{3}{*}{ SDF-1a } & low-level baseline & 160 & 0.749 & 300 & 0.783 \\
\hline & high-level baseline & 129 & $(0.417-1.321)$ & 329 & $(0.429-1.431)$ \\
\hline & & & $P=0.310$ & & $P=0.427$ \\
\hline
\end{tabular}




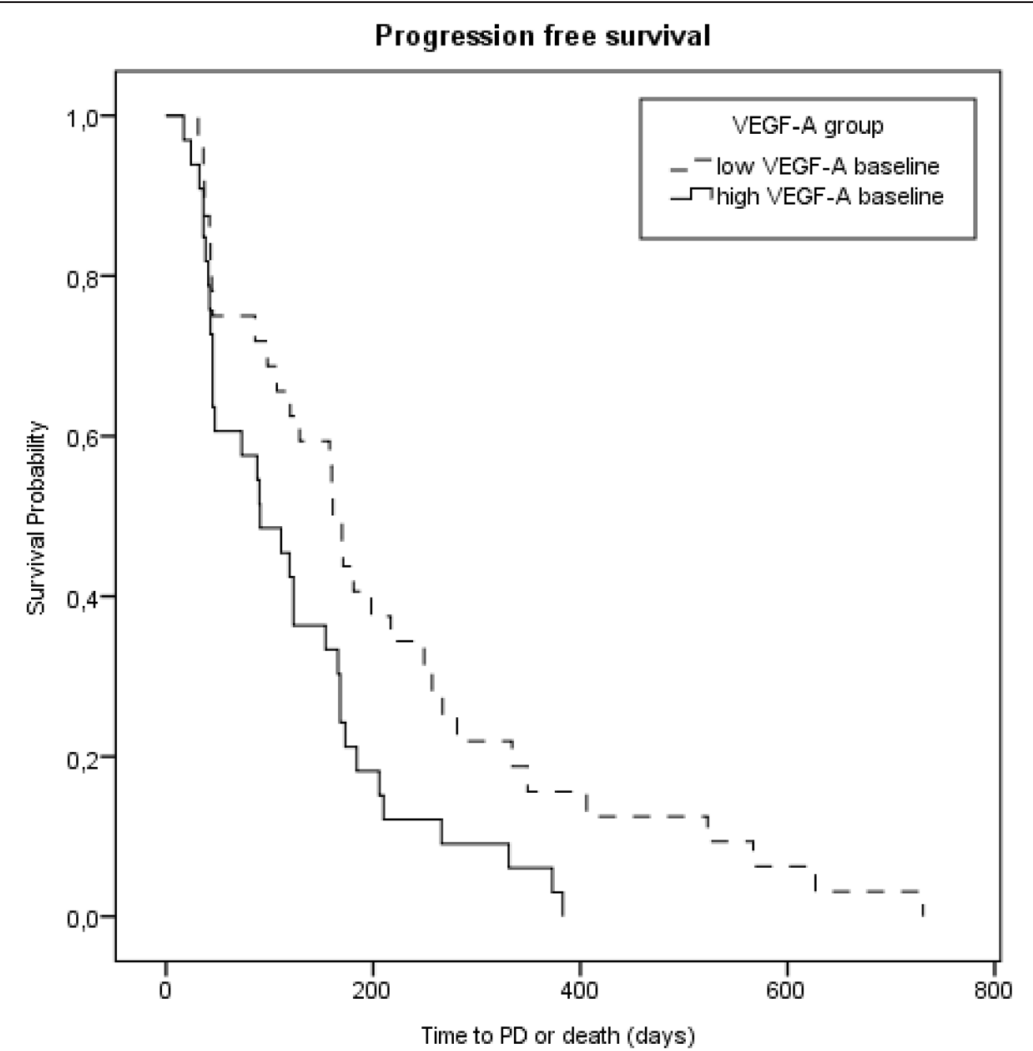

Fig. 3 Kaplan-Meier curves for progression-free survival depending on VEGF-A at baseline dichotomized at the median 58.7 pg/l. Hazard ratio $0.533,95 \% \mathrm{Cl} 0.318-0.895, P=0.017$

\section{Discussion}

Patients with chemorefractory AGC have a poor prognosis. After failure of first-line treatment, various options for second-line treatment have been analyzed in previous studies, but median OS has always remained below 10 months. Recent randomized phase III trials of second-line chemotherapy versus BSC have reported even lower OS times [6, 7, 31]. Here, FOLFIRI has been considered to be an established option after failure of a platinum-containing first-line therapy [2]. Other TKIs such as erlotinib and gefitinib have been under investigation in the first- and second-line treatment of gastric cancer [17, 32, 33]. Ramucirumab, a fully humanized monoclonal antibody targeting VEGFR2, recently showed a significant OS benefit as second-line monotherapy and in combination with paclitaxel $[34,35]$.

In our study, a beneficial effect of SUN added to FOLFIRI on the endpoints PFS, OS and duration of disease stabilization could not be verified. The primary endpoint, PFS, was similar for FOLFIRI + SUN versus FOLFIRI + PL. Regarding OS however, patients receiving SUN had a trend towards a better OS with a median OS of 315 versus 270 days compared with PL. In terms of OS, the benefit of second-line therapy versus BSC has already been demonstrated in trials such as those of
Thuss-Patience et al. and Kang et al. [6, 7]. Two previous second-line, phase II studies with SUN alone reported medians for PFS of 1.3 and 2.3 months and for OS of 5.8 and 6.8 months, respectively [28, 29]. Even if cross study comparison has limitations, FOLFIRI combined with SUN showed an additional improvement with respect to those endpoints compared to SUN or FOLFIRI alone.

Generally, the combination of SUN and FOLFIRI was well tolerated. No unexpected toxicities occurred in patients receiving SUN, demonstrating the safety of such a second-line combination. These data are consistent with a phase I dose-escalation study of the FOLFIRI + SUN regimen [36] and a study of SUN alone in patients with chemorefractory AGC. With respect to non-hematological AEs, diarrhea, vomiting, and lethargy were also most frequent in patients being treated with the higher dose of $37.5 \mathrm{mg} /$ day SUN [36]. The higher frequency of nonhematological toxicities observed in the current study may be attributed to the backbone chemotherapy or underlying disease, characterized by the weaker general condition of second-line AGC patients [28]. Similar studies investigating FOLFIRI in patients with AGC have reported neutropenia, anemia, nausea, diarrhea, and stomatitis as common toxicities as observed in our study [37, 38]. The 


\section{Progression free survival}

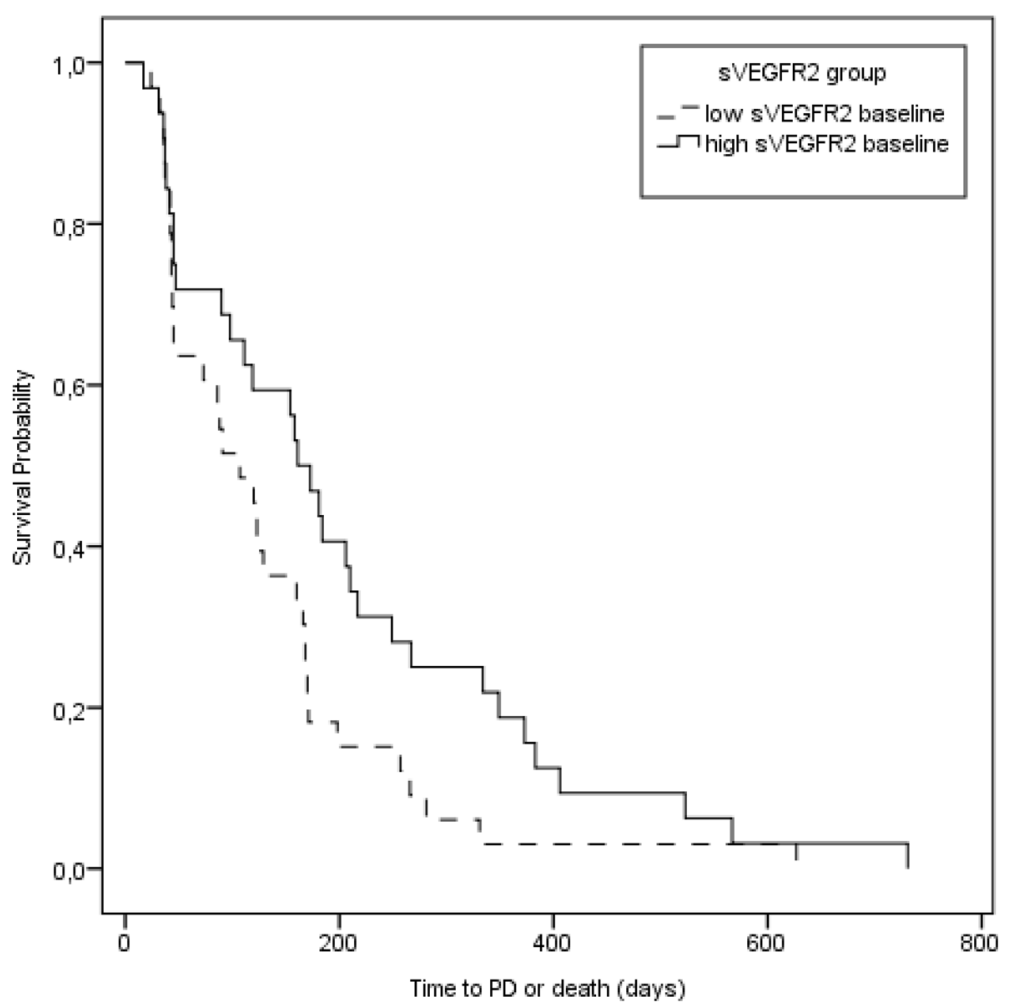

Fig. 4 Kaplan-Meier curves for progression-free survival depending on sVEGFR2 at baseline dichotomized at the median $4688 \mathrm{pg} / \mathrm{ml}$. Hazard ratio $2.557,95 \% \mathrm{Cl} 1.248-5.237, P=0.010$

FOLFIRI combination with daily $37.5 \mathrm{mg}$ SUN versus PL has also been investigated in patients with metastatic colorectal cancer (mCRC) [39]. This phase III study was stopped prematurely due to the occurrence of more grade $\geq 3$ AEs with SUN than PL and a high incidence of toxicity-related deaths. However, these differences between the treatment arms were less marked in our study compared with those observed in patients with mCRC. Since toxicity-related deaths were also less frequent, the lower daily dose of $25 \mathrm{mg}$ SUN may be a more attractive dose level for combination with FOLFIRI. As indicated by Park et al. [40] quality of life (QoL) should be a consideration when considering second-line therapies. Based on the EORTC QLQ-C30 and HADS questionnaires, QoL in our trial was nearly always in favor of SUN (data not shown).

Serum was used for biomarker analysis in our study. No adjustment of the platelet factor was performed for the biomarker concentrations. Both serum and plasma VEGF levels have been reported as prognostic biomarker for survival in gastric cancer and other tumors [12, 41]. Nevertheless, the appropriate specimen to analyze have been discussed extensively in previous literature. For instance Lee et al. suggested serum analysis for VEGF level determination even being affected by platelet-derived VEGF [42, 43].
With regard to the tested biomarkers in our analysis, SUN induced a significant decrease in sVEGFR2 concentration during the first 6 weeks of treatment. Interestingly, higher sVEGFR2 levels during the first 6 weeks of study treatment indicated a longer PFS independent of treatment group. With respect to VEGF-A serum levels, firstly a decrease was observed after 14 days treatment combined with a VEGF-A increase after treatment rest in the SUN group. Additionally, an increase in VEGF-D levels in SUN-treated patients during the first 6 weeks of therapy was observed. High VEGFA baseline levels were prognostic for shorter PFS in both study groups. Additionally, a trend towards shorter OS was shown for patients with a high VEGF-A baseline. A significant improvement in PFS or OS with respect to VEGF-D levels was noted for patients with objective response during treatment only. These findings confirm previous investigations suggesting VEGF$\mathrm{A},-\mathrm{D}$ and sVEGFR2 as potential prognostic biomarkers for therapy-resistant patient outcome [12, 44]. Here, our results highlight again the complexity of the pathomechanisms and the difficulties in the treatment of GC, as no identified biomarker level change during SUN treatment directly correlated with response or survival benefit $[45,46]$. 
Progression free survival - no objective response

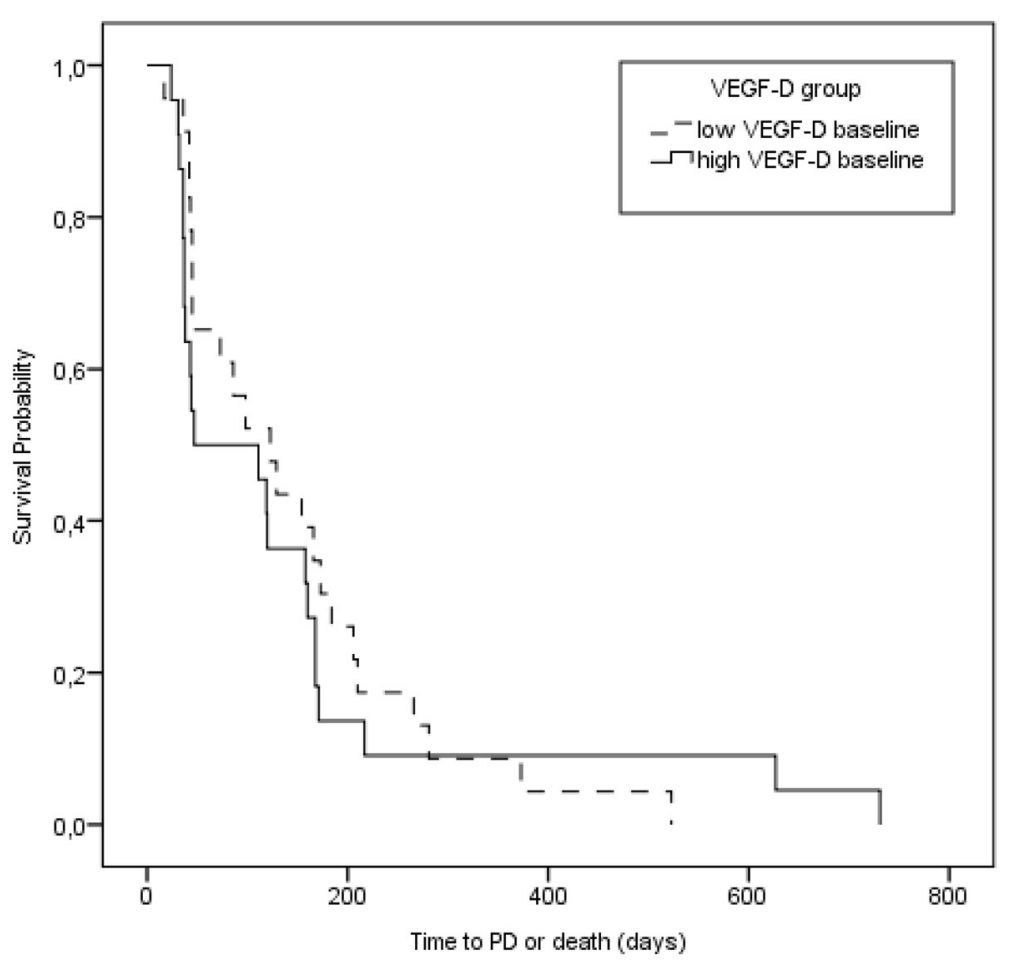

Progression free survival - objective response

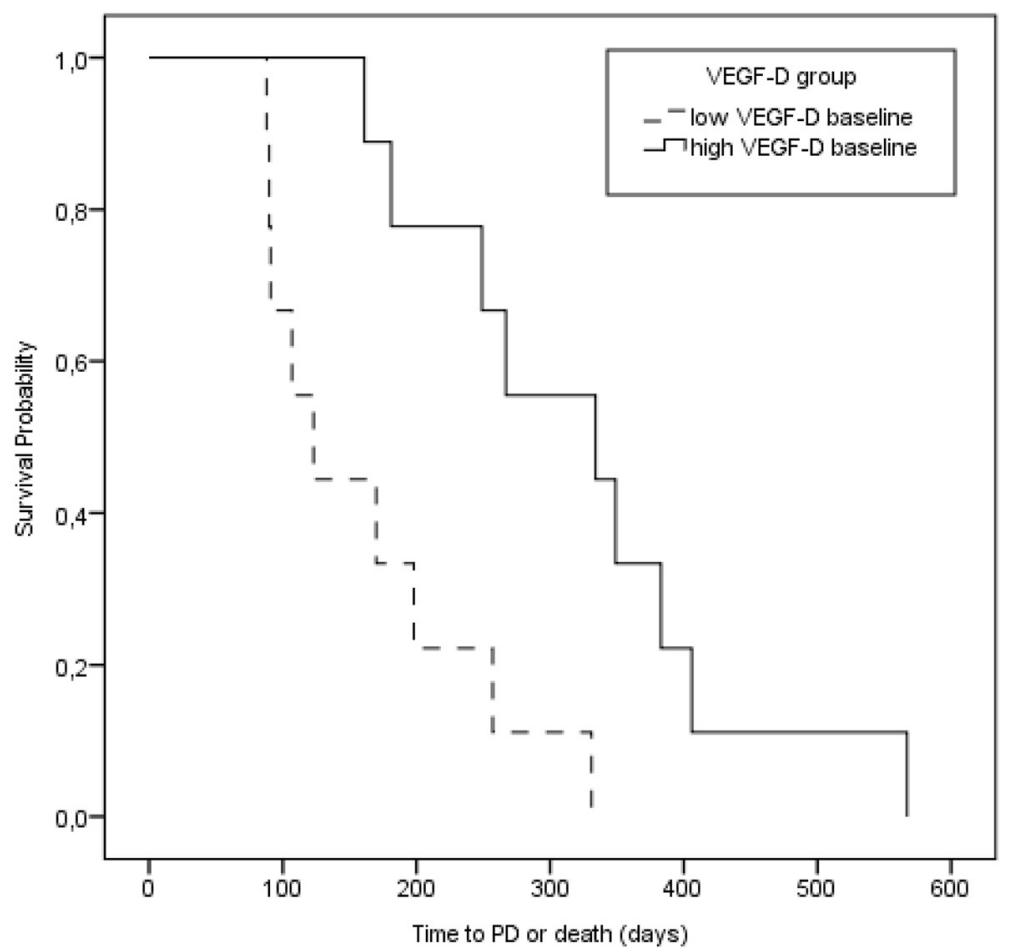

Fig. 5 Kaplan-Meier curves for progression-free survival depending on VEGF-D baseline and objective response dichotomized at the median $>712$ pg/l. Patients without objective response: Hazard ratio for VEGF-D: 1.192, $95 \%$ Cl 0.657-2.164, $P=0.56, N=46$. Patients with objective response: Hazard ratio for VEGF-D: $0.189,95 \% \mathrm{Cl} 0.056-0.637, P=0.007, N=18$ 


\section{Conclusion}

In summary, although FOLFIRI + SUN demonstrated positive trends in overall survival times, the study did not meet its primary endpoint. The median PFS was similar in both groups. Nevertheless, to our knowledge, no biomarker results under these treatment regimens have been published to show the effects on in-vivo angiogenesis. Thus, novel therapy concepts targeting sVEGFR2 and other VEGF group members to normalize vascularization in therapy-resistant tumor tissue should be developed together with biomarkers, such as serum or protein expression levels during anticancer treatment [47].

\section{Additional files}

Additional file 1: Inclusion and exclusion criteria of the SUN-CASE clinical trial protocol. (DOCX $16 \mathrm{~kb}$ )

Additional file 2: Ethics Committees that approved the SUN-CASE clinical trial. (DOCX $18 \mathrm{~kb}$ )

\section{Acknowledgements}

The authors would like to thank the investigators and patients who participated in this trial. Special thanks go to Ulrike Krahn, Rejane Bager and Isabell Hoffmann for statistical analysis, Mrs. Sybille Neufang for their enduring efforts throughout the study. This study was supported by the grant "Clinical Trial Center, funding numbers FKN 01 KN0703 and FKN 01KN1103, IZKS Mainz" of the German Federal Ministry of Education and Research. The manuscript is at least in parts based on the results of the medical theses of Irina Gepfner-Tuma, Armeen Aslan, Kathrin Schlichting and Jens Weusmann. The Johannes Gutenberg-University Mainz, Germany, has agreed to the publication of these results.

\section{Funding}

Preliminary data were presented at the 2013 ASCO Annual Meeting, Chicago, IL, USA. This study was primarily under sponsorship and funding of Mainz University, also supported by the German Federal Ministry of Education and Research grant "Clinical Trial Center, FKN 01 KN0703 and FKN 01KN1103, IZKS Mainz". Educational and research funding was provided by Pfizer, Berlin and medac, Germany to University Mainz, Germany.

\section{Availability of data and materials}

Not applicable yet, as patient issues are still pending.

\section{Author's contributions}

MM designed, planned and coordinated the study. IGT and AM planned and performed the biomarker analysis and interpretation of the biomarker results. MM and IGT collaboratively interpreted all sets of data in the final analysis. MM and IGT with PTP, JR and SHB drafted the manuscript. The authors HW, $\mathrm{SAB}, \mathrm{MR}, \mathrm{FW}, \mathrm{HS}, \mathrm{FK}, \mathrm{LF}$ and JS revised it critically for important intellectual content. AM, JW, SK, and CS were involved in preparation of study and interpretation of data. MO, LS and PG contributed to study design and coordination. JK was responsible for analysis and interpretation of the statistical data. JW analyzed specific clinical sets of study data. The authors MM, PTP, JR, SHB, HW, SAB, MR, FW, HS, FK, LF, JS, JW, SK, CS, PG identified patients, obtained clinical material and coordinated the study in the participating centers. All authors read and approved the final manuscript.

\section{Competing interests}

During the last 5 years, MM and FK received honoraria for educational lectures or travel support (< $500 € /$ year ) by the company Pfizer Germany. All other authors declare that they have no competing interests.

\section{Consent for publication}

Not applicable.

\section{Ethics approval and consent to participate}

This study was approved by the leading ethics committee of the Medical Association of Rhineland-Palatinate, Mainz, in coordination with the participating ethics committees on September 16, 2009 (Reference number: 837.283.09 (6789). The ethics committees involved are listed in a separate file (Additional file 2). All patients have given their written informed consent before participating in the trial.

\section{Author details}

${ }^{1}$ University Medical Center, Johannes Gutenberg-University Mainz, I. Medizinische Klinik und Poliklinik, Langenbeckstraße 1, 55131 Mainz, Germany. ${ }^{2}$ Charité Campus Virchow-Klinikum, Berlin, Germany. ${ }^{3}$ University Hospital Halle (Saale), Halle (Saale), Germany. ${ }^{4}$ Hämatologisch-Onkologische Praxis Eppendorf, Hamburg, Germany. ${ }^{5}$ Kliniken Essen-Mitte - Evang. Huyssens-Stiftung, Essen, Germany. ${ }^{6}$ Krankenhaus Nordwest, Frankfurt, Germany. ${ }^{7}$ Evangelisches Krankenhaus Bielefeld, Bielefeld, Germany. ${ }^{8}$ Kliniken Nordoberpfalz - Klinikum Weiden, Weiden, Germany. ${ }^{9}$ Gesundheitszentrum St. Marien GmbH, Amberg, Germany. ${ }^{10}$ Klinikum rechts der Isar, Technical University Munich, Munich, Germany. ${ }^{11}$ Leopoldina Krankenhaus, Schweinfurt, Germany. ${ }^{12}$ Marienkrankenhaus Darmstadt, Darmstadt, Germany.

${ }^{13}$ Praxisgemeinschaft für Onkologie und Urologie, Wilhelmshaven, Germany. ${ }^{14}$ Interdisciplinary Center for Clinical Trials (IZKS), Mainz, Germany. ${ }^{15}$ Institute of Medical Biostatistics, Epidemiology and Informatics (IMBEI) of the University Medical Center Mainz, Mainz, Germany.

Received: 13 January 2016 Accepted: 20 August 2016

Published online: 31 August 2016

\section{References}

1. Cunningham D, Starling N, Rao S, Iveson T, Nicolson M, Coxon F, Middleton G, Daniel F, Oates J, Norman AR. Capecitabine and oxaliplatin for advanced esophagogastric cancer. N Engl J Med. 2008;358(1):36-46.

2. Wagner AD, Unverzagt S, Grothe W, Kleber G, Grothey A, Haerting J, Fleig WE. Chemotherapy for advanced gastric cancer. The Cochrane database of systematic reviews. 2010;3, CD004064.

3. Lordick F, Kang YK, Chung HC, Salman P, Oh SC, Bodoky G, Kurteva G, Volovat C, Moiseyenko VM, Gorbunova V, et al. Capecitabine and cisplatin with or without cetuximab for patients with previously untreated advanced gastric cancer (EXPAND): a randomised, open-label phase 3 trial. Lancet Oncol. 2013;14(6):490-9.

4. Pasini F, Fraccon AP, Dem G. The role of chemotherapy in metastatic gastric cancer. Anticancer Res. 2011;31(10):3543-54.

5. Ajani JA. Evolving chemotherapy for advanced gastric cancer. Oncologist. 2005;10 Suppl 3:49-58.

6. Thuss-Patience PC, Kretzschmar A, Bichev D, Deist T, Hinke A, Breithaupt K Dogan Y, Gebauer B, Schumacher G, Reichardt P. Survival advantage for irinotecan versus best supportive care as second-line chemotherapy in gastric cancer-a randomised phase III study of the Arbeitsgemeinschaft Internistische Onkologie (AIO). Eur J Cancer. 2011;47(15):2306-14.

7. Kang JH, Lee SI, Limdo H, Park KW, Oh SY, Kwon HC, Hwang IG, Lee SC, Nam E, Shin DB, et al. Salvage chemotherapy for pretreated gastric cancer: a randomized phase III trial comparing chemotherapy plus best supportive care with best supportive care alone. J Clin Oncol. 2012;30(13):1513-8.

8. Drescher D, Moehler M, Gockel I, Frerichs K, Muller A, Dunschede F, Borschitz T, Biesterfeld S, Holtmann M, Wehler T, et al. Coexpression of receptor-tyrosine-kinases in gastric adenocarcinoma-a rationale for a molecular targeting strategy? World journal of gastroenterology : WJG. 2007;13(26):3605-9.

9. Maeda K, Chung YS, Ogawa Y, Takatsuka S, Kang SM, Ogawa M, Sawada T, Sowa M. Prognostic value of vascular endothelial growth factor expression in gastric carcinoma. Cancer. 1996;77(5):858-63.

10. Takahashi Y, Cleary KR, Mai M, Kitadai Y, Bucana CD, Ellis LM. Significance of vessel count and vascular endothelial growth factor and its receptor (KDR) in intestinal-type gastric cancer. Clin Cancer Res. 1996;2(10):1679-84.

11. Blank S, Deck C, Dreikhausen L, Weichert W, Giese N, Falk C, Schmidt T, Ott K. Angiogenic and growth factors in gastric cancer. J Surg Res. 2015;194(2):420-9.

12. Van Cutsem E, de Haas S, Kang YK, Ohtsu A, Tebbutt NC, Ming Xu J, Peng Yong W, Langer B, Delmar P, Scherer SJ, et al. Bevacizumab in combination with chemotherapy as first-line therapy in advanced gastric cancer: a biomarker evaluation from the AVAGAST randomized phase III trial. J Clin Oncol. 2012;30(17):2119-27. 
13. de Haas S, Delmar P, Bansal AT, Moisse M, Miles DW, Leighl N, Escudier B, Van Cutsem E, Carmeliet P, Scherer SJ, et al. Genetic variability of VEGF pathway genes in six randomized phase III trials assessing the addition of bevacizumab to standard therapy. Angiogenesis. 2014;17(4):909-20.

14. Park do J, Seo AN, Yoon C, Ku GY, Coit DG, Strong VE, Suh YS, Lee HS, Yang HK, Kim HH, et al. Serum VEGF-A and Tumor Vessel VEGFR-2 Levels Predict Survival in Caucasian but Not Asian Patients Undergoing Resection for Gastric Adenocarcinoma. Ann Surg Oncol. 2015;22 Suppl 3:1508-15.

15. Karayiannakis AJ, Syrigos KN, Polychronidis A, Zbar A, Kouraklis G, Simopoulos C, Karatzas G. Circulating VEGF levels in the serum of gastric cancer patients: correlation with pathological variables, patient survival, and tumor surgery. Ann Surg. 2002;236(1):37-42.

16. Park do J, Seo AN, Yoon C, Ku GY, Coit DG, Strong VE, Suh YS, Lee HS, Yang HK, Kim HH, et al. Serum VEGF-A and Tumor Vessel VEGFR-2 Levels Predict Survival in Caucasian but Not Asian Patients Undergoing Resection for Gastric Adenocarcinoma. Ann Surg Oncol. 2015;22 Suppl 3:S1508-15.

17. Moehler M, Schwarz S, Wagner AD. Esophagogastric cancer: integration of targeted therapies into systemic chemotherapy. Curr Cancer Drug Targets. 2011;11(6):681-7.

18. Dimberg J, Hugander A, Lofgren S, Wagsater D. Polymorphism and circulating levels of the chemokine CXCL12 in colorectal cancer patients. Int J Mol Med. 2007;19(1):11-5.

19. Arbab AS. Activation of alternative pathways of angiogenesis and involvement of stem cells following anti-angiogenesis treatment in glioma. Histol Histopathol. 2012;27(5):549-57.

20. Fei F, Stoddart S, Muschen M, Kim YM, Groffen J, Heisterkamp N. Development of resistance to dasatinib in $\mathrm{Bcr} / \mathrm{Abl}$-positive acute lymphoblastic leukemia. Leukemia. 2010;24(4):813-20.

21. Strieter RM, Belperio JA, Phillips RJ, Keane MP. CXC chemokines in angiogenesis of cancer. Semin Cancer Biol. 2004;14(3):195-200.

22. Balkwill F. Chemokine biology in cancer. Semin Immunol. 2003;15(1):49-55

23. Nagasawa T, Tachibana K, Kishimoto T. A novel CXC chemokine PBSF/SDF-1 and its receptor CXCR4: their functions in development, hematopoiesis and HIV infection. Semin Immunol. 1998;10(3):179-85.

24. Ying J, Xu Q, Zhang G, Liu B, Zhu L. The expression of CXCL12 and CXCR4 in gastric cancer and their correlation to lymph node metastasis. Medical oncology (Northwood, London, England). 2012;29(3):1716-22.

25. Wang $X$, Zhang $H$, He H, Shen Z, Tang Z, Xu J, Sun Y. Prognostic value of stromal cell-derived factor 1 expression in patients with gastric cancer after surgical resection. Cancer Sci. 2014;105(11):1447-56.

26. O'Farrell AM, Abrams TJ, Yuen HA, Ngai TJ, Louie SG, Yee KW, Wong LM, Hong W, Lee LB, Town A, et al. SU11248 is a novel FLT3 tyrosine kinase inhibitor with potent activity in vitro and in vivo. Blood. 2003;101(9):3597-605.

27. Chow LQ, Eckhardt SG. Sunitinib: from rational design to clinical efficacy. Journal of clinical oncology : official journal of the American Society of Clinical Oncology. 2007;25(7):884-96.

28. Moehler M, Mueller A, Hartmann JT, Ebert MP, Al-Batran SE, Reimer P, Weihrauch M, Lordick F, Trarbach T, Biesterfeld S, et al. An open-label, multicentre biomarker-oriented AlO phase II trial of sunitinib for patients with chemo-refractory advanced gastric cancer. European journal of cancer (Oxford, England: 1990). 2011;47(10):1511-20.

29. Bang YJ, Kang YK, Kang WK, Boku N, Chung HC, Chen JS, Doi T, Sun Y, Shen $L$, Qin $S$, et al. Phase II study of sunitinib as second-line treatment for advanced gastric cancer. Invest New Drugs. 2011;29(6):1449-58.

30. Moehler M, Mueller A, Trarbach T, Lordick F, Seufferlein T, Kubicka S, Geissler M, Schwarz S, Galle PR, Kanzler S, et al. Cetuximab with irinotecan, folinic acid and 5-fluorouracil as first-line treatment in advanced gastroesophageal cancer: a prospective multi-center biomarker-oriented phase II study. Annals of oncology : official journal of the European Society for Medical Oncology / ESMO. 2011;22(6):1358-66.

31. Cook N, Marshall A, Blazeby JM, Bridgewater JA, Wadsley J, Coxon FY. Cougar-02: A randomized phase III study of docetaxel versus active symptom control in patients with relapsed esophago-gastric adenocarcinoma. J Clin Oncol. 2013;31:2013. ASCO 2013. Chicago.

32. Cidon EU, Ellis SG, Inam Y, Adeleke S, Zarif S, Geldart T. Molecular targeted agents for gastric cancer: a step forward towards personalized therapy. Cancers. 2013;5(1):64-91

33. Ferry DR, Dutton S, Mansoor W. Phase III multi-centre, randomised, doubleblind, placebo-controlled trial of gefitinib versus placebo in esophageal cancer progressing after chemotherapy, COG (Cancer Oesophagus Gefitinib). Vienna: ESMO; 2012.
34. Fuchs CS, Tomasek J, Yong CJ, Dumitru F, Passalacqua R, Goswami C, Safran H, dos Santos LV, Aprile G, Ferry DR, et al. Ramucirumab monotherapy for previously treated advanced gastric or gastro-oesophageal junction adenocarcinoma (REGARD): an international, randomised, multicentre, placebo-controlled, phase 3 trial. Lancet. 2014;383(9911):31-9.

35. Wilke H, Muro K, Van Cutsem E, Oh SC, Bodoky G, Shimada Y, Hironaka S, Sugimoto N, Lipatov O, Kim TY, et al. Ramucirumab plus paclitaxel versus placebo plus paclitaxel in patients with previously treated advanced gastric or gastro-oesophageal junction adenocarcinoma (RAINBOW): a doubleblind, randomised phase 3 trial. Lancet Oncol. 2014;15(11):1224-35.

36. Starling N, Vazquez-Mazon F, Cunningham D, Chau I, Tabernero J, Ramos FJ, Iveson TJ, Saunders MP, Aranda E, Countouriotis AM, et al. A phase I study of sunitinib in combination with FOLFIRI in patients with untreated metastatic colorectal cancer. Ann Oncol. 2012;23(1):119-27.

37. Jeon EK, Hong SH, Kim TH, Jung SE, Park JC, Won HS, Ko YH, Rho SY, Hong YS. Modified FOLFIRI as second-line chemotherapy after failure of modified FOLFOX-4 in advanced gastric cancer. Cancer Res Treat. 2011;43(3):148-53.

38. Kim SG, Oh SY, Kwon HC, Lee S, Kim JH, Kim SH, Kim HJ. A phase II study of irinotecan with bi-weekly, low-dose leucovorin and bolus and continuous infusion 5-fluorouracil (modified FOLFIRI) as salvage therapy for patients with advanced or metastatic gastric cancer. Jpn J Clin Oncol. 2007;37(10):744-9.

39. Carrato A, Swieboda-Sadlej A, Staszewska-Skurczynska M, Lim R, Roman L, Shparyk Y, Bondarenko I, Jonker DJ, Sun Y, De la Cruz JA, et al. Fluorouracil, leucovorin, and irinotecan plus either sunitinib or placebo in metastatic colorectal cancer: a randomized, phase III trial. Journal of clinical oncology : official journal of the American Society of Clinical Oncology. 2013;31(10):1341-7.

40. Park SH, Lee WK, Chung M, Bang SM, Cho EK, Lee JH, Shin DB. Quality of life in patients with advanced gastric cancer treated with second-line chemotherapy. Cancer Chemother Pharmacol. 2006;57(3):289-94.

41. Mross K. Inhibition of the VEGF receptor system with tyrosine kinase inhibitors. Angiogenesis inhibition in oncology. Pharm Unserer Zeit. 2008;37(5):404-15.

42. Lee JK, Hong YJ, Han CJ, Hwang DY, Hong SI. Clinical usefulness of serum and plasma vascular endothelial growth factor in cancer patients: which is the optimal specimen? Int J Oncol. 2000;17(1):149-52.

43. Mross K, Scheulen M, Strumberg D, Kuhlmann J, Kanefendt F, Sorgel F, Jaehde U, Burkholder I, Moritz B, Buchert M. FOLFIRI and sunitinib as firstline treatment in metastatic colorectal cancer patients with liver metastases-a CESAR phase II study including pharmacokinetic, biomarker, and imaging data. Int J Clin Pharmacol Ther. 2014;52(8):642-52.

44. Moehler M, Maderer A, Schimanski C, Kanzler S, Denzer U, Kolligs FT, Ebert MP, Distelrath A, Geissler M, Trojan J, et al. Gemcitabine plus sorafenib versus gemcitabine alone in advanced biliary tract cancer: a double-blind placebo-controlled multicentre phase II AIO study with biomarker and serum programme. European journal of cancer (Oxford, England : 1990). 2014;50(18):3125-35.

45. Brossa A, Grange C, Mancuso L, Annaratone L, Satolli MA, Mazzone M, Camussi G, Bussolati B. Sunitinib but not VEGF blockade inhibits cancer stem cell endothelial differentiation. Oncotarget. 2015;6(13):11295-309.

46. Norton KA, Han Z, Popel AS, Pandey NB. Antiangiogenic cancer drug sunitinib exhibits unexpected proangiogenic effects on endothelial cells. OncoTargets and therapy. 2014;7:1571-82.

47. Collet G, Lamerant-Fayel N, Tertil M, El Hafny-Rahbi B, Stepniewski J, Guichard A, Foucault-Collet A, Klimkiewicz K, Petoud S, Matejuk A, et al. Hypoxia-regulated overexpression of soluble VEGFR2 controls angiogenesis and inhibits tumor growth. Mol Cancer Ther. 2014;13(1):165-78.

\section{Submit your next manuscript to BioMed Central and we will help you at every step:}

- We accept pre-submission inquiries

- Our selector tool helps you to find the most relevant journal

- We provide round the clock customer support

- Convenient online submission

- Thorough peer review

- Inclusion in PubMed and all major indexing services

- Maximum visibility for your research

Submit your manuscript at www.biomedcentral.com/submit 